\title{
Defining a Closed-Loop U.S. Aluminum Can Supply Chain Through Technical Design and Supply Chain Innovation
}

\author{
JACK BUFFINGTON ${ }^{1,3}$ and RAY PETERSON ${ }^{2}$ \\ 1.-Department of Industrial Marketing, Royal Institute of Technology, Stockholm, Sweden. \\ 2.-Aleris International, Inc., Cleveland, OH, USA. 3.-e-mail: johnbuff@kth.se
}

\begin{abstract}
The purpose of this study is to conduct a supply chain material flow analysis (MFA) for the U.S. aluminum can market, consistent with studies conducted for the overall worldwide aluminum industry. A technical definition of the use of alloys 5182 and 3104 is conducted by metallurgists for use in the "aluminum can" MFA. Four propositions are created: technical, economic, and supply chain factors are as important to secondary aluminum recycling in an aluminum can as higher recycling rates $\left(\mathrm{P}_{1}\right)$; the development of a unialloy aluminum can will increase reuse rates, but recycling rates must increase for this to happen $\left(\mathrm{P}_{2}\right)$; a closed-loop aluminum can supply chain is not able to be fully realized in today's environment but is very useful for understanding improvement through both supply and demand $\left(\mathrm{P}_{3}\right)$; and UBC supply can improve through a "voluntary deposit-refund system" approach $\left(\mathrm{P}_{4}\right)$.
\end{abstract}

\section{INTRODUCTION}

While aluminum recycling rates in the United States have reached their highest level in a decade to $58.1 \%$, ${ }^{a}$ these rates are significantly lower than in nations such as Sweden that has a nominal rate hovering around $90 \% .{ }^{1}$ This, alongside higher recycling rates in the 11 deposit law states in the United States of $70-75 \%$, has led researchers to conclude that a national mandated "bottle bill" must be enacted nationwide in the United States to curb the massive amounts of aluminum used beverage containers (UBCs) that are being disposed into landfills on a daily basis. ${ }^{2}$ Most research studies have focused on the supply side of the problem (getting consumers/producers to recycle) and often point to nations such as Sweden as being environmentally conscious consumers, who are willing to clean, separate, and deposit their UBCs to achieve higher rates of recycling collection.

Antithetically, it may seem obvious that higher recycling rates will lead to higher recycled content in a new aluminum can, but this is not clear from extant literature. ${ }^{3}$ In an efficient market environment, a

asome experts suggest that the increase in aluminum recycling rates in the United States is largely due to a change in accounting that allows imported used beverage containers to be counted rather than an increase in domestic can collection. closed-loop supply chain system would exist for UBCs to be recycled, remanufactured, and available to the consumer in 60 days ${ }^{b}$ without a significant use of prime (new) aluminum material to supplement the remanufacturing of an aluminum can. Aluminum is the most technically viable packaging material from a reusability standpoint, but from a supply chain standpoint, it is far from efficient: the accumulative stock of aluminum in the United States in 2009 was in the form of bauxite stock (2\%), in use stock (48\%), and the remaining $50 \%$ in landfills, or hibernating stock. ${ }^{5}$

From an environmental/ecological standpoint, optimization may be defined as close to a $100 \%$ reuse factor as possible, with unused UBCs seen as the waste of a resource. However, from an economics standpoint, equilibrium may exist currently in an unregulated environment between supply and demand, and these lower recycling rates in the United States may be "close to efficient" for a variety of reasons. ${ }^{6}$ In this study, we will develop a material flow of a hypothetical closed-loop aluminum can supply chain in the United States to better understand the balance between its supply and demand. The completion of a material flow analysis (MFA), consistent with that done by the International Aluminum Institute (IAI)

\footnotetext{
${ }^{\mathrm{b}}$ Green and Skillingberg ${ }^{4}$ in 2006 noted this as a concept, but it is unclear as to whether reuse content rates really can support this claim.
} 
for the worldwide aluminum supply chain, will be used as our model because no such "aluminum can material flow" exists in the literature. From a material standpoint, an aluminum can of this MFA is a dual-alloy aluminum can design (3104 for the body and 5182 for the end and tab), and a current recycled content rate of approximately 33-50\%, depending on the source. ${ }^{\mathrm{C}}$

After the literature review is conducted, the technical design of the existing dual-alloy aluminum can design (3104 and 5182) will be established through the guidance of industry metallurgists.

In contrast to the conventional wisdom from extant literature that is primarily focused on recycling rates, this analysis will determine the reusable content percentage of the can to achieve effectiveness in recycling. Last, conclusions and future research considerations will be developed.

\section{LITERATURE REVIEW}

\section{Aluminum Can Technical Design}

Aluminum is the second most consumed metal ${ }^{7}$ and the "metal of choice" in the consumer beverage industry, starting in 1959 when Bill Coors invented the seamless aluminum can. Per pound, fabricated aluminum is roughly nine times more energy intensive as glass, but an aluminum can consists of less than $0.5 \mathrm{oz}$; therefore, only $1 / 13$ as much material as a 12 -ounce bottle. ${ }^{8}$ Advancements in the lightweighting of cans have led to a $27 \%$ reduction in materials, with the same can weighing 0.66 of an ounce in the 1960 s versus 0.48 today. ${ }^{9}$ As a result, an aluminum can is roughly 50\% less energy intensive than a glass bottle and is significantly more recyclable. The structural strength of the aluminum can, through the use of a minimum amount of material, occurs through the use of an aluminum alloy 3104, and the shape of the can, including being thicker and domed at the bottom, a necked top, and a lid made of a different alloy $5182^{8}$ and through pressurization. For an industry made up of approximately 100 billion cans sold in the United States ${ }^{4}$ translating into roughly one can used per American per day, ${ }^{9}$ this is a significant design accomplishment, but this success may have inadvertently compromised the viability of recycling and reuse ${ }^{\mathrm{d}}$ efforts as a result.

\footnotetext{
${ }^{\mathrm{c}}$ Novelis (Atlanta, GA) is the largest supplier of rolled sheet aluminum in the United States, and states its recycled content at $33 \%$, as per its 2011 Sustainability Report. In a 2009 presentation, Alcoa (Pittsburgh, PA) noted that $50 \%$ of its can body stock is formed of scrap.
}

${ }^{\mathrm{d}} \mathrm{A}$ difference between recycling and reuse is an important distinction in this article. A recycled can is defined as one that is able to be reused, and a reused material is factored into a new can.
The dual-alloy aluminum can has a body alloy $(98 \% \mathrm{Al}, 1.15 \% \mathrm{Mg}, 0.9 \% \mathrm{Mn})$ that is materially different than the lid/tab design $(95.1 \% \mathrm{Al}, 4.65 \%$ $\mathrm{Mg}, 0.25 \% \mathrm{Mn}$ ) due to the lightweighting objective. Magnesium is a key element in the alloy of aluminum because it increases strength. The dual-alloy design creates a problem for UBC recycling because the mixing of the two alloys disables the purpose of each of the alloys. Manganese improves strength, ductility, and hot rolling processes in aluminum production. ${ }^{10}$ Because aluminum and magnesium are both reactive metals, their separation is difficult, which compounds the problem. Chlorination can occur to reduce the magnesium content, which poses other problems related to toxicity, residues, and damage to the aluminum material. ${ }^{11}$ According to an industry expert metallurgist, this chlorination process will only reduce magnesium by $0.01-0.20 \%$, and it is very expensive to use. Another approach to consider is the selective oxidation of magnesium through various techniques, such as the use of a rotary furnace, versus conventional casting techniques.

An alternative to transforming a dual-alloy UBC mix into two separate alloys is the research and development of a unialloy can, if it is able to meet current weight, strength, and quality specifications, as well as improve recycling/reuse capabilities through its uniformity. In its FY2012 Sustainability Report, Novelis has a stated goal of an aluminum can with $80 \%$ recycled content, in comparison to today's $33-50 \%$ rate; an $80 \%$ target is more reasonable than $100 \%$ due the challenges of recycling a dual-alloy can, and the need of almost doubling collection rates (in the United States) to even achieve that rate. ${ }^{12}$ In this report, Novelis acknowledges its current research for a unialloy aluminum can to mitigate some of these present-day recycling problems.

\section{Aluminum Can Supply Chain System}

To understand its supply chain processes, the aluminum industry has been successful in the use of MFA, a mass balance process whose results are used to estimate the use, reuse, material recovery rates, and other aspects of flow and stocks within a system. Figure $1^{13}$ provides the MFA analysis completed for the aluminum industry for 2010 . From this analysis, it is found that approximately $57 \%$ of secondary aluminum $^{\mathrm{e}}$ is used to produce aluminum ingot (to be processed into semi-fabricated and finished product aluminum), which is an increase from $52 \%$ in $2009 .{ }^{6}$ Because industrial scrap is easier to recycle/reuse and is purer than UBC, only $35 \%$ of the secondary aluminum originates from old scrap, which includes UBC. These numbers shown in Fig. 1 represent the

${ }^{\mathrm{e}}$ It needs to be understood that secondary aluminum includes both recycled industry and postconsumer material, not just the latter. 


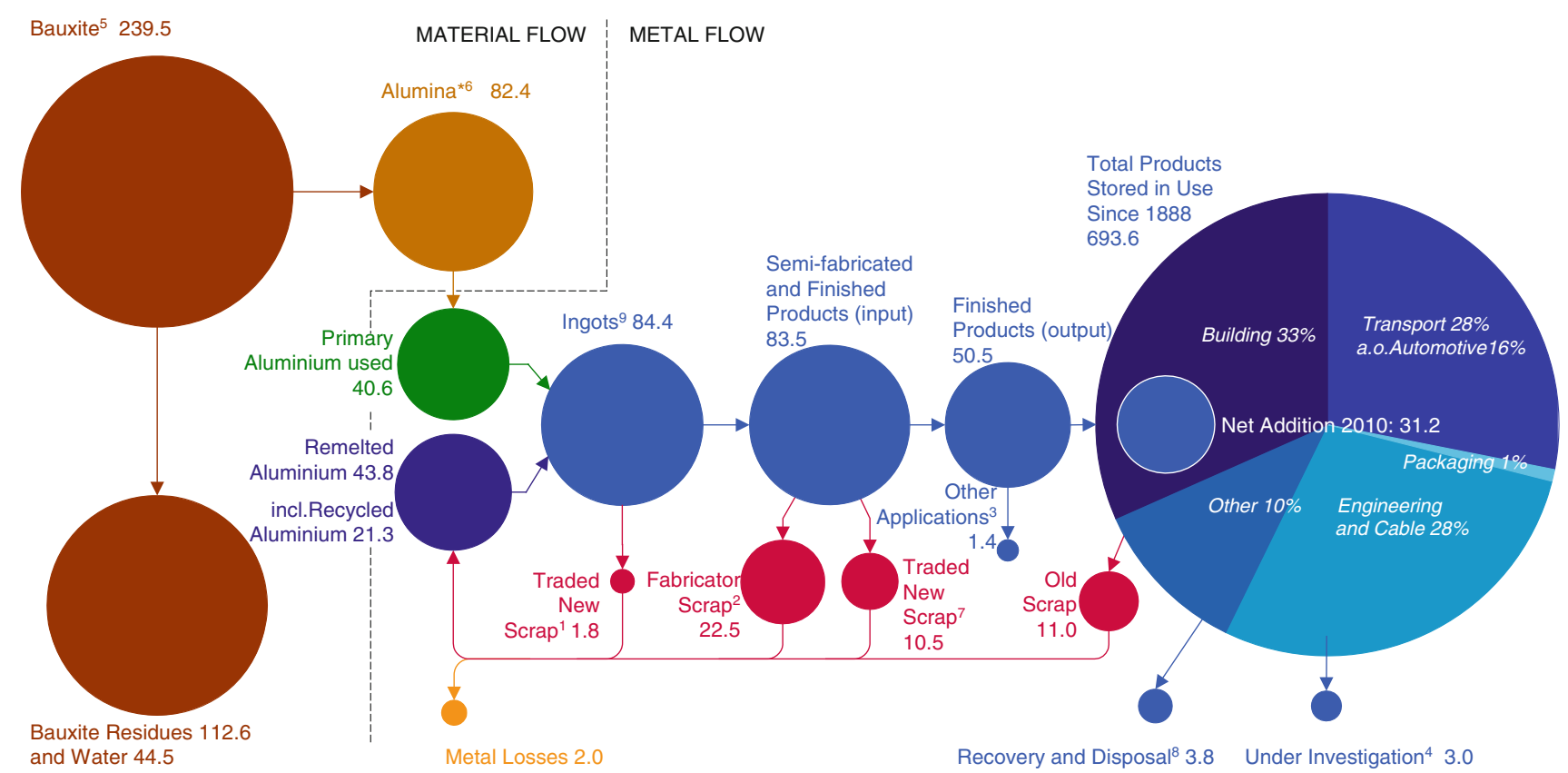

Fig. 1. Global aluminum flow 2010 (International Aluminum Institute 2010). Values in millions of metric tonnes. Values might not add up due to rounding. *Change in stocks not shown. (1) Aluminum in skimmings; (2) scrap generated by foundries, rolling mills, and extruders (most is internal scrap and not taken into account in statistics); (3) such as deoxidation aluminum (metal property is lost); (4) area of current research to identify final aluminum destination (reuse, recycling, recovery, or disposal); (5) calculated based on IAI LCI report, update 2010 (includes, depending on the ore, between $30 \%$ and $50 \%$ alumina); (6) calculated (includes on a global average $52 \%$ aluminum); (7) scrap generated during the production of finished products from semis; (8) either incinerated with/without energy recovery, material recovery, or disposal; (9) estimated stock decrease 890,000 tonnes.

entire aluminum supply chain to include uses other than can packaging, such as building and transportation, and in the extant literature.

The MFA diagram in Fig. 1 is shown as one distinctive flow, yet there are significant differences between the primary and secondary aluminum supply chain processes. Industrial recycled aluminum plants range from 5,000 to 1 million tons per year of recycled metal. ${ }^{14}$ In a theoretical closed-loop process of aluminum can recycling, the net metal yield could be up to $98 \%,{ }^{15}$ and from "scrap to reuse," the process can take as little as 60 days. ${ }^{4}$ While there is significant uniformity across the beverage industry in the use of a standard can design (3104/5182), the use of two distinctively different alloys leads to supply chain and technical problems ${ }^{3}$; in contrast, the use of recycled aluminum content in building and transportation markets may be easier from a supply chain standpoint (acquisition of recycled content is in economies of scale), but may be less standard from a design standpoint.

There are greater challenges for a closed-loop system (large geography, high consumption per capita, and logistics) in the U.S. aluminum can supply chain system in comparison to Europe. In comparison, an American purchases 351 aluminum cans in a year per capita (or 99.8 billion in total) versus a Swede who purchases 103 cans per capita (or 916 million in total), which is about ten times greater of a supply chain problem/opportunity. ${ }^{16}$ Therefore, Sweden's $75 \%$ effective recycling rate ${ }^{f}$ is able to be absorbed outside of its theoretical closedloop supply chain system (within a collaborative EU market), which would not be possible in the United States, especially given the size of its annual consumption market of close to 100 billion cans. There are opportunities to reuse UBCs in the United States outside of its closed-loop system, but these markets also have their own streams of secondary aluminum, with alloy standards that may not be compatible with the levels of magnesium and manganese in the combined UBC alloy. There is also the challenge of the role of the U.S. consumer in this closed-loop recycling model that is a greater challenge than that of the European. ${ }^{17}$

In managing the secondary aluminum markets, municipalities, scrap dealers, and/or brokers play a key role in increasing the aggregation of cans and a captive source/quality assured supply. ${ }^{14}$ The nondeposit states in the United States have a voluntary system of intermediation among producers, consumers, landfills, and import markets in managing supply and demand via brokers, suppliers, and municipalities. In this "market-driven model," an estimated 30 million tons of UBCs exist in U.S. landfills, valued at $\$ 50-\$ 75$ billion at current pri-

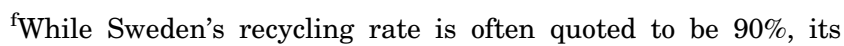
effective rate, net of imports, is approximately $75 \%$. 
ces, and every year this increases by 1 million tons and $\$ 2.5$ billion. $^{18}$ Yet despite the hypothetical values associated with these inventoried landfills, UBCs do not appear to have sufficient value to be urban mined, or for the pace of new UBC added to landfills to be slowed or halted.

From a supply chain economics standpoint, a closed-loop aluminum can supply chain will only utilize recycled content when it is advantageous to do so, ${ }^{19}$ when an adequate supply exists, and when it is driven largely by processing and production costs. ${ }^{20}$ In the United States, recycling is a relatively new business model where technologies and systems are developing and is not yet cost beneficial. ${ }^{21}$ In the book, The Economics of Waste, Porter noted that "recycling does not pay off for the average municipality in the United States, with the bottom line being negative at this point." ${ }^{22}$ In fact, the revenues from the sale of recyclables offsets only $35 \%$ of the total municipal recycling program $\operatorname{costs}^{19}$; however, these programs reduce disposal costs at landfills, which may not be factored into these economics. ${ }^{23}$ In some countries, it is found that prorecycling policies will end up driving rates beyond their economic equilibrium. ${ }^{\text {99 }}$ In such an artificially imposed model, an economic model cannot be created where aluminum can production is tied to the concept of recycling and reuse. ${ }^{24} \mathrm{~A}$ market environment devoid of market failures and imperfection may create an efficient level of recycling. ${ }^{25}$

An artificial increase of supply and the corresponding reduction in prices may lead to recycling continuing to lose money, with this effect not being changed until collection flow matches demand. ${ }^{26}$ For studies conducted in various countries, the most effective recycling policies have been such where incentives drive both supply and demand. ${ }^{19}$ While can recycling programs have been found to be successful in some nonprofit affinity groups such as the Boy Scouts, ${ }^{4}$ a mass market recycling program through consumers in the United States is impacted by economics and employment/wage levels, with a can's scrap value worth approximately 1-2 cents a can (in the United States), not including deposit costs. ${ }^{\text {g }}$

Void of a true economic equation for recycling, a program's success in the United States is largely dependent on the public's willingness to pay for services (like in Germany and Sweden) that is not justifiable. ${ }^{19}$

\section{Aluminum Can Recycling Policies in the United States}

The current available landfill capacity in the United States is estimated to be 3.6 billion tons, or roughly 28 years of disposal at current rates, ${ }^{28}$ while other studies have found even greater landfill

${ }^{\mathrm{g}} \mathrm{A}$ recent article in the Wall Street Journal $(9 / 24 / 12)^{27}$ found a UBC can to be worth about 2.6 cents, assuming 32 cans in a pound, but this seems to be higher than other market sources. capacity farther out into the future. ${ }^{19}$ Approximately $31 \%$ of municipal waste in the United States is recovered and diverted from landfills and incinerators ${ }^{28}$ much lower than Sweden, which diverts practically all waste to reuse or incineration. The average American creates almost twice the amount of municipal solid waste (MSW) as he or she did in the $1960 \mathrm{~s}, 29$ and all efforts to manage waste are factored at the state and local levels; ${ }^{19}$ this is also in contrast to Sweden, which faces EU, federal, state, and municipal mandates/regulations. In the United States, consumers and producers are simply encouraged to recycle/reuse, but with the exception of deposit laws in eleven states; these are voluntary programs with limited financial benefits and cultural acceptance.

Of the 39 non-"bottle bill" states, 32 have sought and failed to implement a bottle bill, yet no state that has ever enacted a "bottle bill" has ever repealed it. ${ }^{16}$ Most notably, the California Beverage Container Recycling and Litter Reduction Act sought to achieve an $80 \%$ recycling rate, primarily through the use of a deposit/refund program, ${ }^{30}$ and it has surpassed this target, with a 2011 recycling rate of $97 \%$.

Oregon was the first state with a "bottle bill" in 1971, with the latest state to enact being Hawaii in 2005. Michigan enacted a 10 cent deposit while the other ten states have a 5 cent deposit, which is significantly lower than 15 cent deposit in place throughout Sweden. In Massachusetts, the state government keeps the unclaimed deposits on containers, while in the other ten states, these monies are kept by retailers and distributors, ${ }^{29}$ which may lead to an unintended disincentive.

Most notably, the argument against a "bottle bill" is the added cost of the package to the consumer/ producer pair, yet some research has found this claim to be of question. ${ }^{32}$ Culturally, most Americans may not possess the conviction to participate in a mandatory recycling deposit/refund system, as exists in Sweden, instead preferring the convenience of curbside recycling. From the 1990s into the first decade of the 21st century, 10,000 recycling centers developed nationwide, but have since matured/consolidated to 5,000 in buying back aluminum cans. ${ }^{33}$

\section{METHODOLOGY AND RESULTS}

From interviews and validations with two metallurgists in the industry in different geographical regions and using different recycling technologies, a metallurgical analysis of the present state technical design of the two alloy aluminum can (AA3104 and AA5182) was conducted to calculate the maximum secondary aluminum content capable in an aluminum can, using two different methodologies: The

\footnotetext{
${ }^{\mathrm{h}}$ According to Calrecycle in $2012,{ }^{31}$ similarly, as has been discussed in other regions, such as Sweden, official recycling rates can be difficult to measure, given the "ins and outs" of import/ exports of cans within other jurisdictions and industries.
} 
first is the redesign of the 3104 and 5182 alloys through a dilution/additive method (model 1), as noted in Eqs. 1 (reconfigured 3104) and 2 (reconfigured 5182):

$$
\begin{aligned}
& \text { Reconfigured } 3104_{1} \text { (Body) }=\left(\left(\mathrm{Mg}_{3104} / \mathrm{Mg}_{\mathrm{UBC}}\right)\right. \\
& \left.\quad \times \mathrm{Mg}_{\mathrm{UBC}}\right)+\left(\left(\mathrm{Mg}_{3104} / \mathrm{Mg}_{\mathrm{UBC}}\right) \times \mathrm{Mn}_{\mathrm{UBC}}\right) \\
& \quad+\left(\left(\mathrm{Mg}_{3104} / \mathrm{Mg}_{\mathrm{UBC}}\right) \times \mathrm{Al}_{\mathrm{UBC}}\right)+\mathrm{Al}_{\text {Prime }}+\mathrm{Mn}_{\text {Prime }}
\end{aligned}
$$

where $\mathrm{Mg}_{3104}, \mathrm{Mn}_{3104}, \mathrm{Al}_{3104}$ are the content requirements for 3104 alloy; $\mathrm{Mg}_{\mathrm{UBC}}, \mathrm{Mn}_{\mathrm{UBC}}, \mathrm{Al}_{\mathrm{UBC}}$ are the UBC contents of each chemical element; and $\mathrm{Al}_{\text {Prime }}, \mathrm{Mn}_{\text {Prime }}$ are the additive prime content to dilute $\mathrm{Mg}(\mathrm{Al})$ and additive to properly design $\mathrm{Mn}$, respectively.

$$
\begin{aligned}
& \text { Reconfigured } 5182_{1}(\mathrm{Lid} / \mathrm{Tab})=\left(\left(\mathrm{Mn}_{5182} / \mathrm{Mn}_{\mathrm{UBC}}\right)\right. \\
& \left.\quad \times \mathrm{Mg}_{\mathrm{UBC}}\right)+\left(\left(\mathrm{Mn}_{5182} / \mathrm{Mg}_{\mathrm{UBC}}\right) \times \mathrm{Mn}_{\mathrm{UBC}}\right) \\
& \quad+\left(\left(\mathrm{Mn}_{5182} / \mathrm{Mn}_{\mathrm{UBC}}\right) \times \mathrm{Al}_{\mathrm{UBC}}\right)+\mathrm{Al}_{\text {Prime }}+\mathrm{Mg}_{\text {Prime }}
\end{aligned}
$$

where $\mathrm{Mg}_{5182}, \mathrm{Mn}_{5182}, \mathrm{Al}_{5182}$ are the content requirements for 5182 alloy; $\mathrm{Mg}_{\mathrm{UBC}}$ and $\mathrm{Mn}_{\mathrm{UBC}}$, $\mathrm{Al}_{\mathrm{UBC}}$ are the UBC contents of each chemical element; and $\mathrm{Al}_{\text {Prime }}$ and $\mathrm{Mg}_{\text {Prime }}$ are the additive prime contents to dilute $\mathrm{Mn}(\mathrm{Al})$ and additive to properly design $\mathrm{Mg}$, respectively.

In model 1, the method to "dilute" UBC is a function of chemical material that needs to be reduced; for 3104, magnesium needs to be reduced, with the amount of UBC to be retained in the new redesign alloy is a ratio of the magnesium specification for 3104 divided by the content of magnesium in the mixed UBC alloy; the same method is chosen for 5182 but manganese is reduced. Once this material is "cut" into the proper composition, prime materials (aluminum/manganese for 3104 and aluminum/magnesium for 5182) are added to complete the composition. From the literature review, as well as interviews with industry metallurgists, it seems that this "dilution method" is relatively safer for reconfiguring UBC to 5182 and 3104 than a chlorination approach. We found that the "dilution method" is the most suitable approach, if magnesium cannot be reduced technically in the remanufacturing process.

In model 2 , we assume that magnesium can be reduced technically through the use of a rotary furnace approach. In this method, the mixed UBC alloy is input into the furnace through a front-end loader or belt conveyor over a 16 -h to 18 -h period. Magnesium removal and "tapping of the furnace" requires $2-4 \mathrm{~h}$ each, respectively, enabling the entire process to occur over a 24 -h period.

In this UBC process, $0.7 \%$ magnesium is removed, which also leads to a corresponding $0.7 \%$ reduction in aluminum for a total $1.4 \%$ loss of material. A $0.1 \%$ additive of manganese must occur for this alloy to be able to achieve the necessary composition for the 3104 body.

\section{Aluminum Can Technical Design Analysis}

To study these two models in determining the optimal technical balance of primary and secondary material for an aluminum can, we engaged a U.S. beverage manufacturer and two industry-leading metallurgists involved in the recycling of aluminum in the United States. To determine the chemical composition of the aluminum can, both in UBC and in new product specification, we worked with the metallurgists to calculate the percentages, understanding that differences can occur within the industry due to a variety of factors, such as actual UBC composition, manufacturing and remanufacturing techniques, supply chain logistics, and the presence of other elements (such as lead and iron) on the UBC from other sources. As a starting point in this technical analysis, we have documented the following progression of the alloy for the aluminum can:

- 1950s: Aluminum cans made from high-purity 1100 series slugs.

- 1960s: 3003 and 3004 alloys began to be used for strength as light weighting became a requirement.

- 1970s: Minor modifications began to 3004 body alloy (such as move to 3104).

- 1980s: Increased magnesium added to end/tab (5182) to meet strength requirements. This decreased the recyclability of the can, in the process.

From our literature review, Ref. ${ }^{10}$, and industry interviews, we found discrepancies in the defined chemical composition of the aluminum can, most notably in the $\mathrm{Mg}$ content in the lid/tab (4.7\% from industry interview and 2.5\% from Cox and Fray, respectively), and we chose the former, given the individual's occupation and it being a more recent source. As shown in Table I, there are significant differences in both the $\mathrm{Mg}$ and $\mathrm{Mn}$ compositions, creating a problem in UBC reuse back into the 3104 and 5182 alloys.

If used at the combined UBC level, the mixed manganese level in UBC would lead to poor characteristics for either alloy relative to the specification. An effective "yield rate" of $89.2 \%$ (metal rate of $92 \% \times$ recovery rate of $97 \%$ ) will leave the UBC at the same alloy composition, but will lead to a loss of $10.8 \%$ due to nonmetal material (paint, coatings, epoxies, contaminants) and losses in the re-manufacturing process. ${ }^{i}$

We will factor this impact in losses in the MFA, as shown in the next section.

Based on the data assumptions and formulas for model 1, we calculated the following properties and processes to calculate the UBC composition of the mixed alloys, the required dilution rates, and the

${ }^{\mathrm{i} A s s u m p t i o n s ~ c a l c u l a t e d ~ b y ~ p a r t i c i p a t i n g ~ m e t a l l u r g i s t s . ~}$ 
Table I. Aluminum can current state design and UBC mixed alloy

\begin{tabular}{lccc}
\hline & \% of Component & & \multicolumn{2}{c}{ UBC of Can } & \multicolumn{2}{c}{ mixed alloy (\%) } \\
\cline { 2 - 2 } Body stock & 98.0 & 79 & 97.4 \\
Aluminum & 1.2 & 77.4 & 1.9 \\
Magnesium & 0.9 & 0.9 & 0.8 \\
Manganese & & 0.7 & 21 \\
End/lid & 95.1 & 20.0 & 1.0 \\
Aluminum & 4.7 & 0.1 & 92 \\
Magnesium & 0.3 & & 97 \\
Manganese & & & \\
Technical & & & \\
Metal rate & & & \\
Recovery rate & & & \\
\hline
\end{tabular}

Table II. Model 1-dilution rates to achieve 3104/5182 specifications

\begin{tabular}{|c|c|c|c|}
\hline & $\begin{array}{l}\text { Weighted } \\
\text { UBC }(\%)\end{array}$ & $\begin{array}{c}\text { Dilution } \\
\text { composition }(\%)\end{array}$ & $\begin{array}{c}\text { New content } \\
\text { (in diluted can) }(\%)\end{array}$ \\
\hline \multicolumn{4}{|c|}{ Body stock (39\% dilution ratio) } \\
\hline Aluminum & & & 98.4 \\
\hline Secondary aluminum & 97.4 & 59.4 & \\
\hline Prime aluminum & & 39.0 & \\
\hline Magnesium & 1.9 & & 1.2 \\
\hline Manganese & 0.8 & $0.4^{*}$ & 0.9 \\
\hline \multicolumn{4}{|c|}{$\mathrm{Lid} / \mathrm{tab}$ (60.7\% dilution ratio) } \\
\hline Aluminum & & & 95.0 \\
\hline Secondary aluminum & 97.4 & 38.3 & \\
\hline Prime aluminum & & 56.7 & \\
\hline Magnesium & 1.9 & 4.0 & $4.7 * *$ \\
\hline Manganese & 0.8 & & 0.3 \\
\hline
\end{tabular}

$* 0.4 \%$ added to achieve $0.9 \%$ in proportion, $* * 4 \%$ added to achieve $4.7 \%$ proportion

UBC content possible in a new can, as shown in Table II.

In model 1 (Table II), the aluminum dilution of the UBC mixed alloy occurs through the addition of prime aluminum of $39 \%$ in the body stock and $56.7 \%$ in the lib/tab stock, respectively; other additives must occur as well to body (Mn) and lib/tab (Mg), which may lead to the complexity of the process. Using this approach, the maximum amount of UBC that can be allowable in the body stock is $61.0 \%$ in the body stock and $39.3 \%$ in the lid/tab stock, for a weighted average of $56.4 \%$. In model 1 , the 3104 manufactured can sheet for a new aluminum can will possess almost $60 \%$ of recycled aluminum content, and less than $38 \%$ for the 5182 sheet. Therefore, from a technical design standpoint and assuming no growth and a closed-loop supply chain system, only $55 \%$ of the mixed UBC alloy can be reused in the making of an aluminum can.

In comparison to the global aluminum MFA, shown in Fig. 1, data from the Aluminum Association note that $59 \%$ of UBC can be combined in a AA3104 body stock and 39\% in total for the can (both alloys); the content reuse statistics from the
Novelis/Alcoa reports between $33 \%$ and $50 \%$. We believe the technical analysis created in model 1 is valid and representative of industry practices, at this first cut look at an aluminum supply chain system.

For model 2, the results are presented, in Table III.

Table I shows the current state composition of $12 \mathrm{oz}$ aluminum can, and the mixed alloy of the UBC.

For model 2, the focus is on the reuse of UBC for 3104 can stock only, given its large percentage of the total can mass and the lower specification related to impurities required for it in comparison to 5182, which has a higher standard. For the purposes of this study, we will assume the economics of acquisition, processing, and remanufacturing of UBC is viable for the $79 \% 3104$ body stock, but not for the 5182 end/lid alloy due to scale and specification standards, as is noted above. If this is the case, then the yields for model 1 and model 2 are shown in Table IV.

From our interviews with metallurgists, we understand that various methods (dilution, chlori- 
Table III. Model 2-rotary furnace process to achieve 3104 specification

\begin{tabular}{lcc}
\hline & \% Alloy & Comments \\
\cline { 2 - 3 } UBC body stock (79\%) & & \\
Aluminum & 97.4 & \\
Magnesium & 1.9 & \\
Manganese & 0.8 & \\
Yield loss & $(10.8)$ & (92\% metal content, 97\% recovery rates) \\
Magnesium loss & $(0.7)$ & Selective separation possible using rotary furnace \\
Aluminum loss & $(0.7)$ & For 3104 can stock only \\
UBC recovery & 87.8 & Requirement to achieve 3104 alloy \\
Mn addition & 0.1 & \\
\hline
\end{tabular}

Table IV. Model yield rates

\begin{tabular}{lccc}
\hline & $\mathbf{3 1 0 4 ,}$ Model 1 (dilution) (\%) & 3104, Model 2 (rotary furnace) (\%) \\
\cline { 2 - 3 } General yield loss & 10.8 & 10.8 \\
Method loss rate & 39 & 1.4 \\
UBC yield rate & 50.2 & 87.8 \\
\hline
\end{tabular}

nation, magnesium reduction, etc.) are being used contingent upon technology availability, production scope (3104 versus 5182), supply/UBC recovery rates, closed-loop leakage, and supply chain logistics. With respect to UBC recovery rates, the use of higher yield remanufacturing techniques may be less important in a nation such as the United States compared with higher rate countries of Sweden and even Brazil. Furthermore, demographical/geographical differences in the United States will also be a factor (lower population density and geographical distance to aluminum mill).

\section{U.S. Aluminum Can Material Flow Analysis}

Next, an aluminum can MFA (consistent to Fig. 1) was developed and is presented below in Fig. 2; given the use of different technical methods in U.S. market, we will factor a $1 / 3-2 / 3$ weighting related to model $1 /$ model 2 , respectively, given geographical/demographical factors. This will net to a $73.5 \%$ net technical recovery rate possible to be used in the MFA model shown below in Fig. 2.

We completed a "closed-loop aluminum can supply chain diagram" for the United States, based on the following criteria already established in this article:

1. Total number of aluminum cans $=100$ billion

2. Weight per can $=0.5 \mathrm{oz}$

3. MFA presented in metric tons (MT)

4. Maximum recyclable content (blended between models 1 and 2) 3104 of $75.3 \%$ and 5182 of $0 \%$

5. UBC yield loss (nonmetal and remanufacturing process) of $10.8 \%$ from metallurgists and consistent with IAI MFA data

6. 3104/5182 technical design per metallurgy expert

7. Technical dilution analysis by metallurgy expert and Aluminum Association analysis
8. Material flow (upstream of metal flow) and metal scrap ratios consistent with IAI MFA analysis

9. For U.S. imported UBC (from other regions, such as Mexico, Europe, and Middle East) taken from CRI report (at 7.8 billion cans a year)

10. Waste percentages in industrial process at $12 \%$ (consistent with IAI MFA) and secondary market viability of non-consumer scrap (new, roll, and fabrication) at $80 \%$, and first priority for reuse versus consumer scrap (UBC).

From this analysis, we found a technical design capability for secondary aluminum to be a weighted average of $75.3 \%$ for 3104 only, and a $44.6 \%$ reuse capacity for UBC, assuming that upstream industrial scrap is preferential (so used first), net of assumed scrap losses. As well, we factored in a $7.8 \%$ import of UBC into the supply chain system (per CRI report) and calculated a possibility of $21.3 \%$ reuse of UBC outside of the closed-loop supply chain system (to other industries, such as automotive). Such a high closed-loop "escape rate" of $21.3 \%$ is reasonable, given the homogenous nature of alloy 3105 (a "vanilla alloy" used in buildings and other general uses), and the viability of exporting UBC at various regions of the country (such as on container ships that are "deadheading" back to Asia). We believe our number is fairly consistent with CRI's estimation of an adjusted (net of exports) domestic recycling rate of $54.5 \%$ because this report does not account reuse as different between the overall aluminum industry. We also conclude that, given the technical design of the present day dual-alloy aluminum can, a $75.3 \%$ recycling rate within 3104 is likely current state optimal, given the difficulties of optimizing to the two separate alloys and the lower UBC collection rates in the United States in com- 


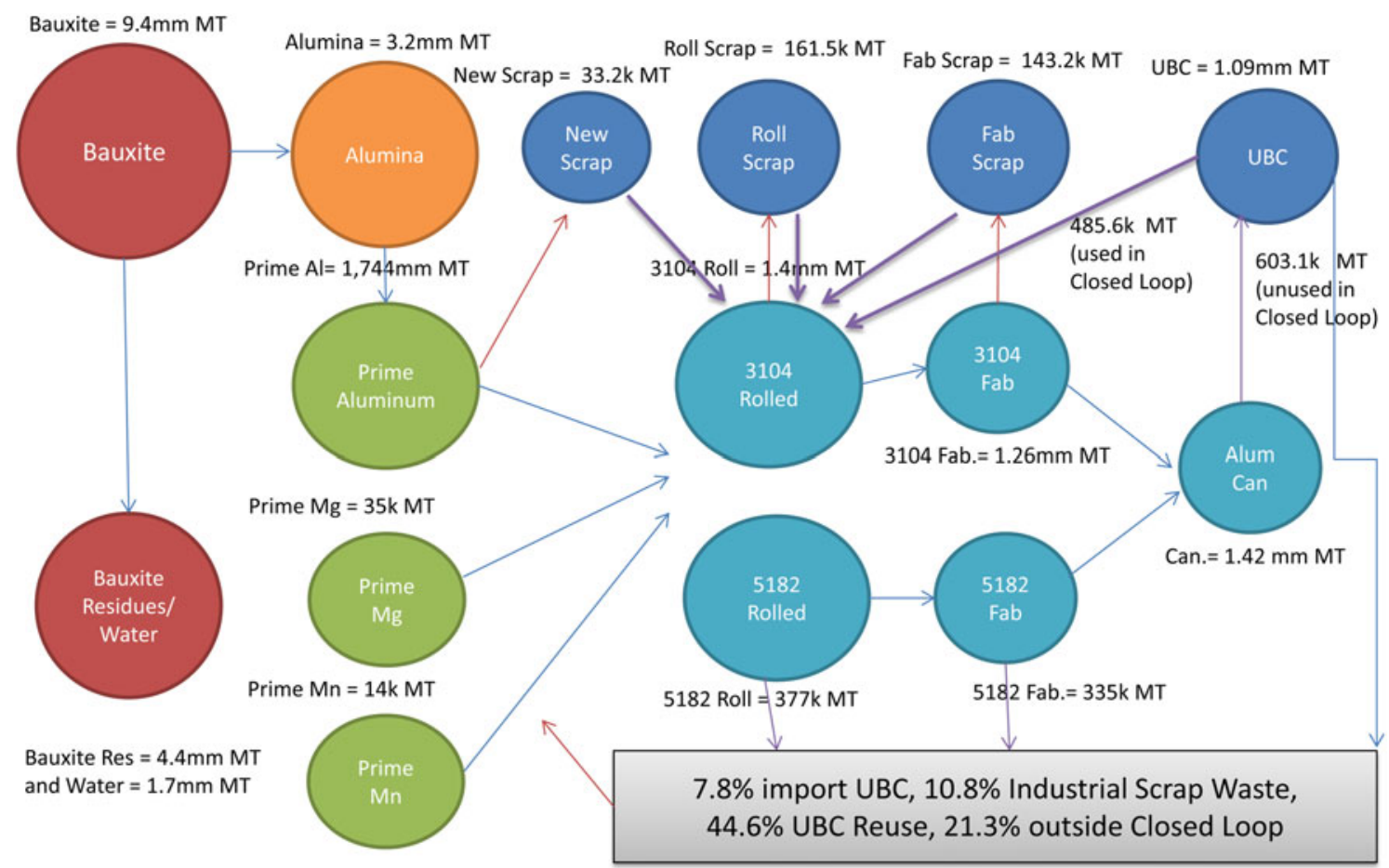

Fig. 2. U.S. aluminum can material flow analysis, assuming 100 billion cans and cans as $0.5 \mathrm{oz}$.

parison to other industrialized nations, particularly in Europe. Last, we found in the literature review of an estimated 1 million tons landfilled annually ${ }^{18}$; in our use of a weighted average methodology of model 1 (dilution of $33 \%$ ) and model 2 (rotary furnace of $66 \%$ ), we estimated $603 \mathrm{k}$ MT landfilled, which appears to be more reasonable of an approximation, given the rising demand, as noted in the research literature. ${ }^{j}$

\section{RESULTS}

From the technical and material flow analyses, the following propositions have been developed:

$\mathbf{P}_{\mathbf{1}}$ : Currently, higher reuse rates are primarily a function of higher recycling collection rates, but in the future these rates could become more a function of technical, manufacturing, and supply chain factors, such as a unialloy can, remanufacturing technology, and improvements in logistics-today, a dual-alloy can design (and specifically the 5182 lid) leads to a suboptimal opportunity for future reuse beyond $75.3 \%$ (with the body comprising of 79\%). The vast geography of the United States, the use of different remanufacturing technologies, and trade flows within supply chain logistics (i.e.,

${ }^{\mathrm{j} A c c o r d i n g}$ to a Wall Street Journal article dated September 24, 2012, both Novelis and Alcoa are increasing their efforts to collect UBC, with Novelis setting up a new organization to collect 60 billion cans a year by 2015 . between the United States and Asia) also leads to reductions in reuse. Therefore, we believe that the issue of $\mathrm{P}_{1}$ is equally a problem of "consumer recycling" and "supplier efficiency and innovation" that needs to be viewed holistically.

$\mathbf{P}_{2}$ : The "UBC recycling/reuse" problem is one equally of both supply and demand-from extant literature and discussion with metallurgists, there seems to be a siloed focus on supply (recycling/UBC collection) and demand (greater reuse/technical design and supply chain logistics), but a lack of a holistic strategy toward the problem. For example, even if recycling rates in the United States improved, there would be technical and economical limitations, due to the design of the can. Conversely, if the technical design of the can was changed to a unialloy design, there would be a lack of UBC supply to achieve greater reuse. The results from this MFA indicate that both elements of supply and demand must be addressed holistically to mitigate this recycling/reuse problem.

$\mathbf{P}_{3}$ : In the aluminum can industry, the concept of a "closed-loop supply chain system" is largely not possible, but it is useful to our understanding of the recycling/reuse (supply/demand problem). From a technical design standpoint, the alloys 3104 and 5182 have been established solely for use for aluminum cans for the beverage industry, which leads to the question of a conceptual "closed-loop supply chain" system. While "recycling back to shelf in 60 days" has been a slogan used in the industry to encourage consumers to recycle, the truth of the matter is, as is shown in our MFA, a best-case 


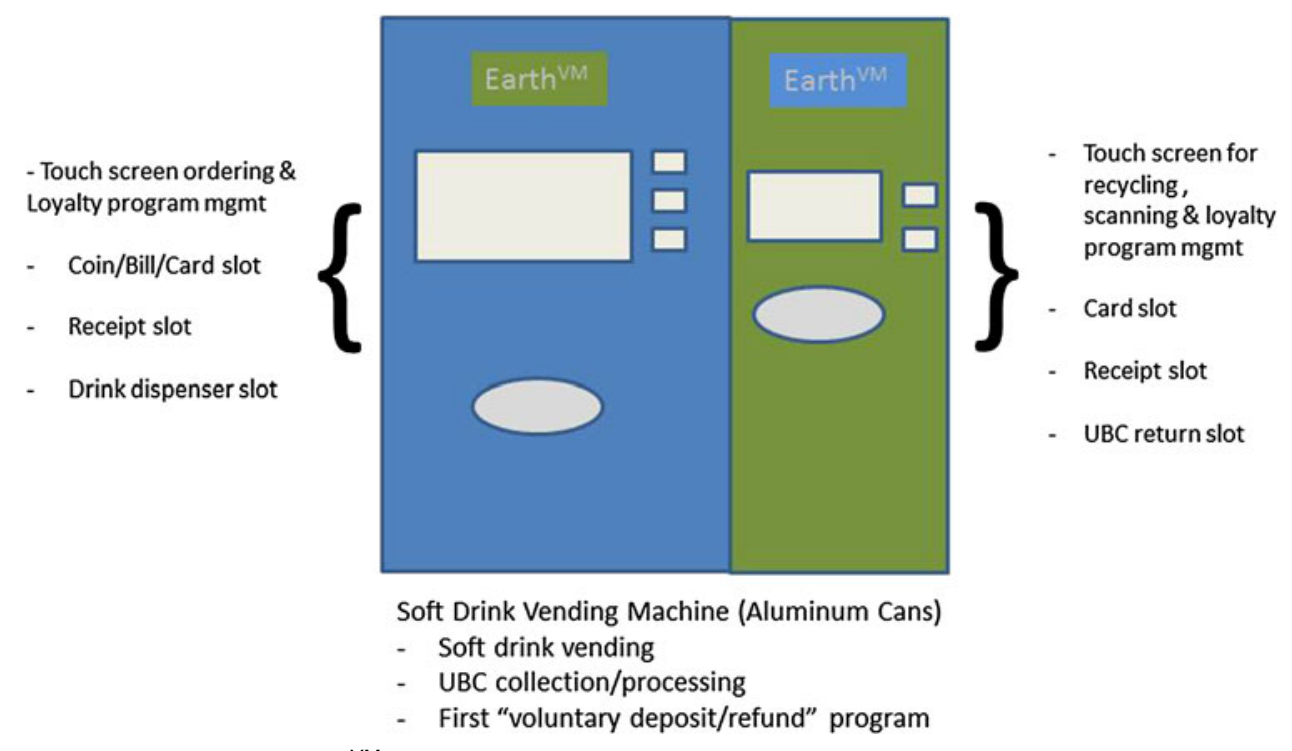

Fig. 3. Voluntary refund/deposit system: Earth ${ }^{\mathrm{VM}}$ (earth vending machine).

closed-loop scenario shows an approximate $40 \%$ of recycled UBC "escapes" to either other industries (3105 for general aluminum, etceteras) or foreign markets (i.e., shipping to Asia on empty return container ships from California). Despite these supply chain challenges, we believe that the consideration of a "closed-loop supply chain system" concept will lead to an aggregate view of the consumer and producer, which can lead to higher (natural) recycling and reuse rates, driving up the price (demand) of UBC, which could lead to the increase of reuse and reduction of waste.

$\mathbf{P}_{4}$ : Improve the UBC supply by establishing a "voluntary deposit/refund system" that becomes a self-funding program through rewarding those who recycle and punishing those who do not (in contrast to a deposit/refund system). We found that while mandated refund/deposit programs in the United States does lead to an increase in supply, it may have an inadvertent effect of reducing UBC market price, therefore discouraging further increases of collection. Therefore, we believe the economics around supply would improve through a self-funded loyalty program that would reward those who already recycle (and not charge them a deposit) while charging a deposit to those who opt-out of recycling. Figure 3 provides a conceptual diagram of the use of a smart reverse vending machine that is attached to the regular soft drink vending machine and records purchase for recycling management in this program.

From these four propositions, we conclude that only a concerted effort that manages a holistic consumersupplier perspective of "reuse and recycling" will lead to improvements in the U.S. aluminum can market. An MFA for the aluminum can industry illustrates the nature of the problem, which justifies this balanced supply and demand approach.

\section{CONCLUSIONS AND FUTURE RESEARCH}

In this study, we analyzed the problem of a market equilibrium within a closed-loop aluminum can supply chain system. We studied the entire supply chain system in the United States to include raw material manufacturing, fabrication, beverage manufacturer use, supply chain logistics, consumption, and postconsumption recycling and reuse. From this analysis, we found the challenges in the United States to be significant, requiring a holistic understanding of reuse and recycling, supply and demand, and technical versus supply chain logistics challenges. From a material flow standpoint, it may be optimal for aluminum cans to be reused outside of the closed loop (in different industries and nations), so the focus must be on (I) increasing the amount of UBC to be collected for reuse (versus disposal) and (II) increasing the yield of recycled material that is reused. These two challenges, considered holistically, should be the focus on researchers seeking to address this problem in the United States.

From our technical analysis of the composition of the aluminum can, we found that industry progress to lightweight and strengthen the can has led to an inadvertent scenario where the amount of recycled content possible in a can is a limiting factor for same purpose reuse. While various innovators are seeking to develop an unialloy aluminum can design that achieves the same lightweighting purpose as the present-state dual-alloy design, the implementation of such a radical design change will pose a challenge to the existing aluminum can supply chain system. This technical challenge, as well as the challenge to increase recycling rates to justify higher reuse rates through design, will require supply chain as well as technical solutions. 
We also believe that it is not as simple as it is made out in extant literature for recycling/reuse rates in the United States to increase to levels currently found in nations such as Sweden and Brazil due to economics, geography, demographics, and culture. If a nationwide mandated program was put in place in the United States, it is not clear as to whether this would increase reuse rates in a cost-effective manner commensurate with the costs associated with such programs. We believe that it will be useful to study other MFA models, such as those in the EU, South America, and Asia to determine the viability of this supply/demand, recycling/reuse, and mandated/natural management of aluminum as a valuable commodity for reuse.

\section{ACKNOWLEDGEMENTS}

We gratefully wish to thank Golden Aluminum, Inc. for their support in the metallurgical analysis of this paper.

\section{REFERENCES}

1. American Recycler (2011), http://www.americanrecycler. com/0811/1091aluminum.shtml.

2. J. Gitlitz and P. Franklin, The 10 Cent Incentive to Recycle (Washington, DC: Container Recycling Institute, 2006).

3. J. Buffington, JOM 64, 923 (2012).

4. J. Green and M. Skillingberg, Light Met. Age, 33 (2006).

5. W. Chen and T. Graedel, Ecol. Econ. 81, 92 (2009).

6. G. Gelles, Aluminum Recycling, ed. M. Schlesinger (Boca Raton, FL: CRC Press, 2007), p. 41.

7. International Aluminum Association, Global Aluminum Recycling: A Cornerstone of Sustainable Development (London, 2010). http://www.world-aluminum.org/cache/fl0000181.pdf.

8. C. McMillan, "Temporal Aluminum Material Flows and Greenhouse Gas Emissions to Evaluate Metals Recycling Allocation in Lifecycle Assessment" (Ph.D. thesis, Lansing, MI: University of Michigan, 2011).

9. J. Liew, "Innovative Product Design for Sustainability Enhancement in Aluminum Beverage Cans" (Masters thesis, Lexington, KY: University of Kentucky, 2005).

10. K. Hagelstein, J. Environ. Manag. 90, 12 (2009).
11. A. Cox and D. Fray, J. Electrochem. Soc. 150, 12 (2003).

12. Novelis Corporation, Novelis FY2012 Sustainability Report (Atlanta, GA: Novelis, 2012).

13. Global Aluminium Industry Sustainability Performance 2010 (London: International Aluminum Institute, 2010).

14. P.A. Plunkert, Aluminum Recycling in the United States (Washington, DC: U.S. Department of the Interior, 2000).

15. U. Boin and M. Bertram, JOM 57(8), 28 (2005).

16. J. Gitlitz, The Role of the Consumer in Reducing Primary Aluminum Demand (Sao Luis, Brazil: Container Recycling Institute, 2003).

17. P. Gonzalez-Torre, L. Adenso-Diaz, and A. Ruiz-Torres, $J$. Environ. Econ. 69, 2 (2003).

18. S. Das, JOM 64, 285 (2012).

19. D. Loughlin and M. Barlaz, Crit. Rev. Environ. Sci. 36, 4 (2006).

20. Z. Luo and A. Soria, A Perspective Study of the Aluminum Industry (Seville: JRC Scientific and Technical Reports, 2007).

21. D. Clement, Recycling-Righteous or Rubbish? (Minneapolis, MN: Federal Reserve Bank of Minneapolis, 2005).

22. R. Porter, The Economics of Waste (Washington, DC: Resources for the Future, 2002).

23. T. Kinnamin, Top. Econ. Anal. Policy 5, 1 (2010).

24. R. Ayres, Metals Recycling: Economic \& Environmental Implications (Fountainebleau: INSEAD, Centre for the Management of Environmental Resources, 1997).

25. T. Tietenberg, Environmental and Natural Resource Economics, 7th ed. (Reading, PA: Addison Wesley, 2006).

26. R. Wright, R. Richey, M. Tokman, and J. Palmer, J. Appl. Bus. Econ. 12, 5 (2011).

27. J. Miller, Wall str. J. (2012). http://online.wsj.com/article/ SB10000872396390443589304577633410750041328.html.

28. S. Magram, Indian J. Sci. Technol. 4, 692 (2011).

29. B. Deitchman, A March of Nickels and Dimes for Recycling: A Present State of Bottle Bills (Ithaca, NY: Cornell University, 2006).

30. T. Beatty, P. Berck, and J. Shimshack, Econ. Inq. 45, 4 (2007).

31. Biannual Report of Beverage Container Sales, Returns, Redemption and Recycling Rates. Calrecycle, Sacramento, November 2012. http://www.calrecycle.ca.gov/bevcontainer/ Notices/2012/Biannual.pdf.

32. University of Maryland, 2011 Impact Analysis of Beverage Container Deposit Program in Maryland (Baltimore, MD: University of Maryland, 2011).

33. G. Kipperberg, Environ. Resour. Econ. 36, 2 (2005). 